OPEN ACCESS

Edited by:

Ana Lucia Pereira,

Universidade Estadual de Ponta

Grossa, Brazil

Reviewed by:

Janina Kahn-Horwitz,

Oranim Academic College, Israel Hu Jian,

Jiangxi University of Finance and

Economics, China

*Correspondence:

Pär Bjälkebring

par.bjalkebring@psy.gu.se

Specialty section:

This article was submitted to

Educational Psychology,

a section of the journal

Frontiers in Education

Received: 27 November 2018 Accepted: 25 March 2019 Published: 18 April 2019

Citation:

Bjälkebring P (2019) Math Anxiety at the University: What Forms of

Teaching and Learning Statistics in

Higher Education Can Help Students

With Math Anxiety? Front. Educ. 4:30.

doi: 10.3389/feduc.2019.00030

\section{Math Anxiety at the University: What Forms of Teaching and Learning Statistics in Higher Education Can Help Students With Math Anxiety?}

\author{
Pär Bjälkebring * \\ Department of Psychology, University of Gothenburg, Gothenburg, Sweden
}

Math anxiety is a feeling of tension, worry, and/or fear in situations involving math-related activities. The relationship between Math anxiety and math cognition has been frequently studied, and the negative associations between the two have been observed at multiple levels of mathematical processing ranging from simple counting to complex math problems. These negative associations are evident across various developmental stages. The aim of this study is to identify teaching and learning methods in higher education that students high in math anxiety use and benefit from. Through an anonymous online survey, psychology students enrolled in a statistics course rated their Math anxiety, Subjective numeracy, and Objective numeracy; in addition, they rated their success in the statistics course and their general preference for different forms of learning (e.g., face to face learning, online course material, as well as the use of the online video material presented on University of Gothenburg's learning management system [GUL]). The results gave no support to the notion that students high in Math anxiety used online teaching tools more than other students. However, students high in Math anxiety said they used their classmates as help to pass the course to a greater extent compared to those lower in Math anxiety.

Keywords: mathematic anxiety, mathematic abilities, blended learning, online learning activity, statistic education

\section{INTRODUCTION}

Stress and anxiety has been identified as one of the major challenges in introductory statistics on the undergraduate level (Bradstreet, 1996). This can pressure students, especially those with low math self-efficacy, considerably (depending on how well student learning is supported), reduce their selfefficacy, and interfere with learning (Betz, 1978). However, so far little is known about how attitudes (such as anxiety) influence teaching and learning in statistics (Ramirez et al., 2012).

Math anxiety can be described as strong negative emotions toward math, and Ashcraft (2002) defines math anxiety as "a feeling of tension, apprehension, or fear that interferes with math performance." Math anxiety, negatively influence math ability through several different pathways, for example working memory when performing math problems (Skagerlund et al., 2019). Math anxiety is related to many math related constructs such as math self-efficacy, however it is separate from the person's actual math ability (Peters and Bjalkebring, 2015). Thus, even though math anxiety is negatively correlated with math ability, a person with high math anxiety can be great at math, and a person without any math anxiety can be bad at math (for overview see Dowker et al., 2016). 
The aim of this study is to identify teaching and learning methods in higher education that students high in math anxiety use and benefit from.

Over a 100 years ago Thomas Edison predicted, in the New York Dramatic Mirror, that "books will soon be obsolete in the schools... It is possible to teach every branch of human knowledge with the motion picture" (Tamim et al., 2011). Today, most academic departments in universities, and to some extent even in k-12 education, have embraced credit-based online learning. In addition, students expect that more information, even in campus-based courses, should be online, and most Universities have introduced digital learning platforms. As a result, instructors have been gradually introducing more online study elements into their classroom teaching (Bates, 2015). Digital learning platforms are used to store lecture notes in the form of slides or PDFs, provide links to online readings, or online forums for discussion. Hence, almost all current faceto-face learning courses have aspects of digital learning, but without changing the basic classroom teaching model (Dede and Richards, 2012). Meaning that aspects of online learning are being blended with traditional teaching. Although there is no standard or commonly agreed definitions in this area, "blended learning" has been suggested as a descriptor for this use of technology. Hence, almost all teachers at my University engage in "blended learning" (Garrison and Kanuka, 2004).

Since the 1960s researchers have tried to compare different teaching styles and evaluate the inclusion of technology to facilitate a better learning environment (Schurdak, 1967). Tamim et al. (2011) identified "well-conducted" comparative studies covering 40 years of research. They concluded that there was a slight positive influence of being taught in a blended learning environment. However, the measured difference was quite weak, and the authors conclude that among everything that influences teaching and learning (aspects of the goals of instruction, pedagogy, teacher effectiveness, subject matter, age level, fidelity of technology implementation, etc.) technology intervention accounts for only a small part of the effect. However, general comparisons between "older" and "newer" types of

TABLE 1 | The relationship between Math anxiety and use as well as perceived benefit for the seven different methods for teaching and learning $(n=65)$.

\begin{tabular}{|c|c|c|c|c|}
\hline & \multicolumn{2}{|c|}{$\begin{array}{l}\text { Student use } \\
\text { of method }\end{array}$} & \multicolumn{2}{|c|}{$\begin{array}{l}\text { Student perceived } \\
\text { benefit of method }\end{array}$} \\
\hline & $r$ & $p$ & $r$ & $p$ \\
\hline (1) Face-to-face lectures & 0.21 & 0.094 & 0.18 & 0.151 \\
\hline (2) Text book & 0.07 & 0.571 & 0.05 & 0.679 \\
\hline (3) Assignments in the text book & -0.03 & 0.807 & 0.15 & 0.230 \\
\hline (4) Online assignments & 0.12 & 0.351 & 0.06 & 0.642 \\
\hline (5) Online lectures on GUL & 0.09 & 0.475 & -0.04 & 0.751 \\
\hline (6) Online lectures on YouTube & 0.04 & 0.754 & 0.05 & 0.698 \\
\hline (7) Help from a friend & 0.39 & $<0.001$ & 0.32 & 0.010 \\
\hline
\end{tabular}

$r$ indicates the Pearson correlation. $p$ indicates the significant level. Alpha level used is 0.05 . teaching and learning tend to favor the latter. It is important to note, where differences have been found, they are often attributed to factors other than the mode of delivery (Bates, 2015). Hence, there is reason to believe that blended learning is especially beneficial for certain individuals. This study will investigate the relationship between a student's math anxiety and use as well as preference for different forms of teaching in a statistics course using blended learning. The teaching methods used were (1) classical face-to-face lectures, (2) a text book, (3) assignments from the text book, (4) online assignments developed by the teacher on the university's learning platform (GUL), (5) online lectures developed by the teacher on the university's learning platform, and (6) online lectures on YouTube; lastly, (7) help from a friend. Methods 1 through 3 are considered classical forms of teaching, while 4 through 6 are considered new forms of teaching; taking help from a friend (7) is considered outside the categorization of new and old teaching, however, represents something students often do and were encouraged to do.

\section{METHOD \\ Participants}

Participants $(n=111)$ were selected from the Gothenburg University Participant pool witch consist of people that have signed up to be contacted about research opportunities. Selection was based on students enrolled in undergraduate classes at the department of psychology during the past 12 months. Sixty-seven participants (60\%) took the survey of those sixty-five participants had been enrolled in a statistic course at the department and two had not, and those two participants were excluded from further analysis. The final sample consists of 65 participants, $36(53.7 \%)$ women, age range $17-59$ years, mean age 24 years $(\mathrm{SD}=6.6$ years $)$.

\section{Procedure}

Participants were sent an email and got a link to the survey, they were first asked to consent to the study. After that they took the survey that consisted of question about their use of different teaching and learning methods in statistics. After that they answered questions about their math anxiety, subjective numeracy and objective numeracy.

\section{Materials}

Use of teaching and learning methods was assessed by seven statements. "In this course to what extent did you use...." (1) face-to-face lectures, (2) the text book, (3) the assignments in the text book, (4) online assignments, (5) online lectures on the university's learning platform (GUL), (6) online lectures on YouTube, and (7) if they took help from a friend. Each question was asked on a 1 (never) to 5 (always) scale.

They were then asked about their perceived benefit from the different methods: "In this course to what extent did you feel your learning benefited from..." method (1) through (7). Each question was asked on a scale from 1 (not at all) to 5 (very much). 
All participants were then asked about their general preference (not only in this statistics class) for face-to-face lectures and for online lectures on a 1-5 scale from not at all to very much.

Math anxiety was assessed by the Alexander and Martray math anxiety test (Alexander and Martray, 1989) asking participants questions about Math anxiety in three different situations on a five-point scale ranging from $1=$ not anxious to $5=$ very anxious; (e.g., "Please indicate your level of anxiety in the following situations: Studying for a math test."). Cronbach's alpha $=0.75$.

Subjective numeracy was assed using Fagerlin's et al. (2007) scale. This scale is an 8-item self-reported measure of ability with and preference for numbers (e.g., "How good are you at working with percentages?", "How often do you find numerical information to be useful?", assessed on a six-point scale). Cronbach's alpha $=0.86$.

Objective numeracy was measured using a six-item scale (e.g., "If the chance of getting a disease is $10 \%$, how many people would be expected to get the disease out of 1,000 ;" adapted from
Weller et al., 2013). Each item was scored as correct or incorrect, and correct items were summed (possible range 0-6). Cronbach's alpha $=0.75$.

\section{RESULTS}

Math anxiety was normally distributed in the sample (mean $=2.96$, median $=3.00, \mathrm{SD}=0.99)$, meaning that participants stated that they would feel at least some anxiety or more in math related situations. Math anxiety was negatively correlated to Subjective numeracy $(r=-0.48, p<0.001)$, but not to Objective numeracy $(r=0.21, p=0.10)$, meaning that participants with higher Math anxiety rated their numeric ability lower but did not score significantly lower on the Objective numeracy test. When looking at gender differences, men scored significantly lower on the Math anxiety measure (men $\mathrm{m}=2.4, \mathrm{SD}=0.83$ ) compared to women (women $\left.\mathrm{m}=3.4, \mathrm{SD}=0.90, t_{(63)}=15.39, p<0.001\right)$. Similarly, when looking at the difference between men and women
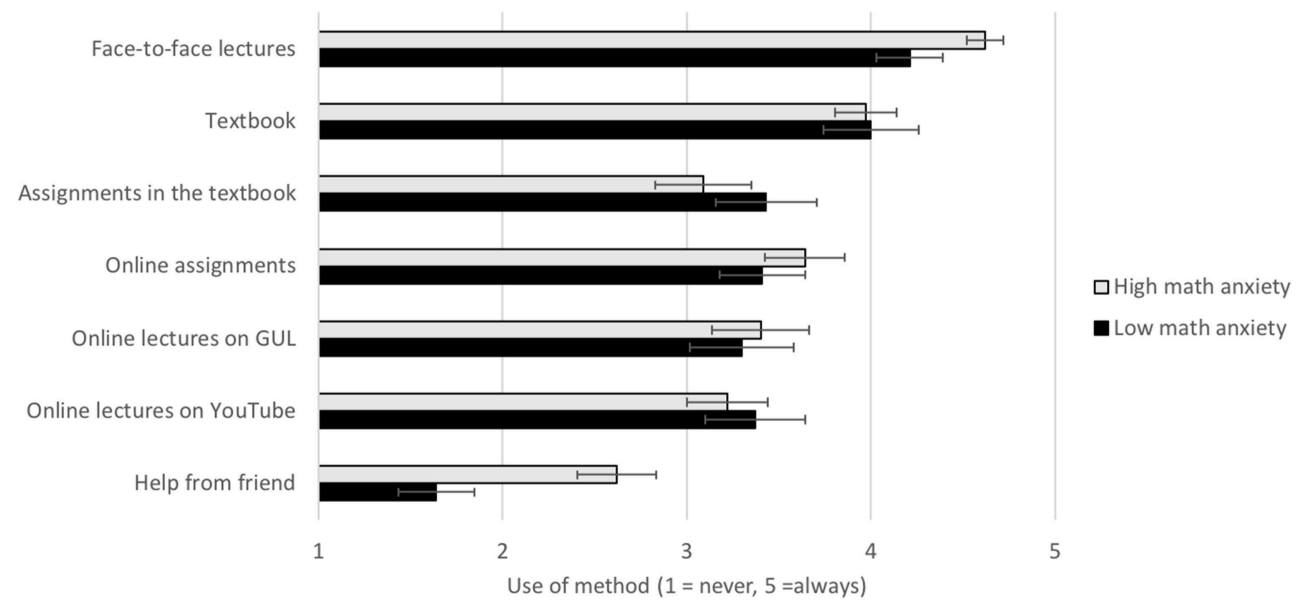

FIGURE 1 | The use of teaching and learning methods by students high and low in Math anxiety $(n=65)$.

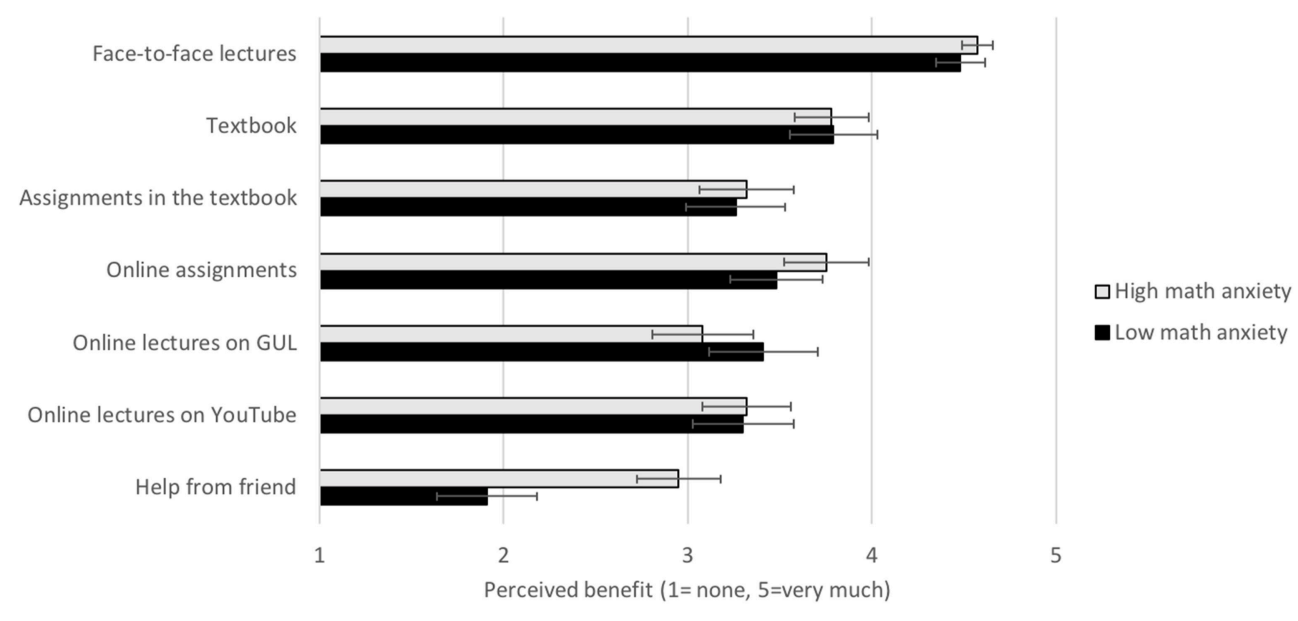

FIGURE 2 | The perceived benefit of teaching and learning methods by students high and low in Math anxiety ( $n=65)$. 
in their own subjective view of their ability, men scored significantly higher on the Subjective numeracy measure (men $\mathrm{m}=4.2, \mathrm{SD}=0.52$, women $\mathrm{m}=3.8, \mathrm{SD}=0.75, t_{(62)}=5.1$, $p=0.027)$. However, there were no differences on the 6item Objective numeracy scale; men averaged 3.2 correct items ( $\mathrm{SD}=1.9)$, while women averaged slightly lower, but not significantly so, 2.5 correct items $\left(\mathrm{SD}=1.7, t_{(63)}=2.6\right.$, $p=0.112$ ).

To assess the relationship between math anxiety and use and benefit of the seven methods of teaching and learning, a correlation analysis was performed (see Table 1). The correlation analysis revealed that the only teaching and learning method that was used more by students with high Math anxiety (vs. students with low Math anxiety) was to take help from a friend (see Figure 1). In addition, the only method that students with high Math anxiety (vs. students with low math anxiety) said helped them more was to receive help from a friend (see Figure 2). To visualize the relationship participants were divided into low math anxiety and high math anxiety based on a median split.

\section{DISCUSSION}

Bates (2015) states that different kinds of students might benefit from different teaching methods within blended learning. The aim of this study was to identify teaching and learning methods in higher education that students high in Math anxiety use and benefit from.

The results showed that Math anxiety was not related to any of the old or new methods of teaching. The only method that students high in math anxiety were more likely to use was receiving help from friends; in addition, taking help from friends was the only method that was perceived as more beneficial by students with high Math anxiety compared to those not suffering from Math anxiety. This indicates that encouraging students to help each other through group assignments and study groups might be especially beneficial for students with Math anxiety (Kingston and Lyddy, 2013). It is likely that all students are not equally socially integrated in the class and hence a buddy system where each student are given a "math buddy" could help students both to socially integrate better but also could give students suffering from math anxiety an important resource (Bush, 2003).

That students high in math anxiety do not indicate that they use or benefit more from new forms of teaching might feel like a disappointment to those of us that try to help students that suffer from math anxiety. However, this means that students that suffer from math anxiety do not show any indication of avoiding any of the teaching and learning methods compared to students without math anxiety. This indicates that both old and new forms of teaching and learning

\section{REFERENCES}

Alexander, L., and Martray, C. (1989). The development of an abbreviated version of the mathematics anxiety rating scale. Measurement Eval. Counsel. Dev. $22,143-150$ can be used with students that suffer from math anxiety. In line with this, research has shown a benefit from online tools that help students; for example, a "massive open online course" (MOOC) for students centered on changing these ideas and teaching students how to learn mathematics well (Boaler et al., 2018). Similar ideas related to boosting self-affirmations have been tested in supporting learning in statistics. Peters et al. (2017) showed that through an affirmation-intervention during a statistics course they produced a positive influence on both students' subjective view of their ability as well as their actual ability.

Limitations with this study are its small sample size and selection. The small sample size is due to student availability. In addition, using real students creates a highly selected sample.

\section{CONCLUSION}

There is not one form of teaching and learning that fits all students; however, when using blended learning all students will benefit from the plethora of methods used (Bates, 2015). Students high in math anxiety say that they use and benefit from the same teaching methods as students low in math anxiety, with the exception of them taking more from help from other students. Hence, group assignments, study groups, and buddy systems could be put in place to provide additional help to students suffering from Math anxiety.

\section{ETHICS STATEMENT}

This study was carried out in accordance with the recommendations of the Board of Research Ethics Review (REC) at the University of Gothenburg. The protocol was approved by the Board of Research Ethics Review at the University of Gothenburg. All subjects gave written informed consent in accordance with the Declaration of Helsinki.

\section{AUTHOR CONTRIBUTIONS}

PB developed the study concept and the study design. Testing and data collection were performed by $\mathrm{PB}$. PB performed the data analysis and interpretation, drafted, and made edits to the manuscript.

\section{FUNDING}

This research was supported by grants from the Swedish Research Council (VR; DNR-2016-00507) and the Swedish Research Council for Health Working-Life and Welfare (FORTE) 2012-0175.
Ashcraft, M. H. (2002). Math anxiety: personal, educational, and cognitive consequences. Curr. Directions Psychol. Sci. 11, 181-185. doi: 10.1111/1467-8721.00196

Bates, A. T. (2015). Teaching in a Digital Age. Available online at: http://opentextbc ca/teachinginadigitalage/ (accessed March 25, 2019). 
Betz, N. E. (1978). Prevalence, distribution, and correlates of Math Anxiety in college students. J. Counsel. Psychol. 25, 441-448. doi: 10.1037/0022-0167.25.5.441

Boaler, J., Dieckmann, J. A., Pérez-Núñez, G., Sun, K. L., and Williams, C. (2018). Changing students minds and achievement in mathematics: the impact of a free online student course. Front. Edu. 3:26. doi: 10.3389/feduc.2018.00026

Bradstreet, T. E. (1996). Teaching introductory statistics courses so that nonstatisticians experience statistical reasoning. Am. Statistician 50, 69-78. doi: 10.1080/00031305.1996.10473545

Bush, G. (2003). The School Buddy System: The Practice of Collaboration. Chicago, IL: American Library Association.

Dede, C., and Richards, J. (eds.). (2012). Digital Teaching Platforms: Customizing Classroom Learning for Each Student. New York, NY: Teachers College Press.

Dowker, A., Sarkar, A., and Looi, C. Y. (2016). Mathematics anxiety: what have we learned in 60 years? Front. Psychol. 7:508. doi: 10.3389/fpsyg.2016. 00508

Fagerlin, A., Zikmund-Fisher, B. J., Ubel, P. A., Jankovic, A., Derry, H. A., and Smith, D. M. (2007). Measuring numeracy without a math test: development of the Subjective Numeracy Scale. Med. Decision Making 27, 672-680. doi: 10.1177/0272989X07304449

Garrison, D. R., and Kanuka, H. (2004). Blended learning: uncovering its transformative potential in higher education. Internet Higher Edu. 7, 95-105. doi: 10.1016/j.iheduc.2004.02.001

Kingston, J. A., and Lyddy, F. (2013). Self-efficacy and short-term memory capacity as predictors of proportional reasoning. Learning Individual Differences 26, 185-190. doi: 10.1016/j.lindif.2013.01.017

Peters, E., and Bjalkebring, P. (2015). Multiple numeric competencies: when a number is not just a number. J. Pers. Soc. Psychol. 108, 802-822. doi: $10.1037 /$ pspp0000019

Peters, E., Shoots-Reinhard, B., Tompkins, M. K., Schley, D., Meilleur, L., Sinayev, A., et al. (2017). Improving numeracy through values affirmation enhances decision and STEM outcomes. PLoS ONE 12:e0180674. doi: 10.1371/journal.pone.0180674

Ramirez, C., Schau, C., and Emmioglu, E. (2012). The importance of attitudes in statistics education. Statistics Edu. Res. J. 11, 57-71. Available online at: https:// psycnet.apa.org/record/2012-33955-004

Schurdak, J. (1967). An approach to the use of computers in the instructional process and an evaluation. Am. Edu. Res. J. 4, 59-73. doi: 10.3102/00028312004001059

Skagerlund, K., Östergren, R., Västfjäll, D., and Träff, U. (2019). How does mathematics anxiety impair mathematical abilities? Investigating the link between math anxiety, working memory, and number processing. PLoS ONE 14:e0211283. doi: 10.1371/journal.pone.0211283

Tamim, R. M., Bernard, R. M., Borokhovski, E., Abrami, P. C., and Schmid, R. F. (2011). What forty years of research says about the impact of technology on learning a second-order meta-analysis and validation study. Rev. Edu. Res. 81, 4-28. doi: 10.3102/0034654310393361

Weller, J. A., Dieckmann, N. F., Tusler, M., Mertz, C. K., Burns, W. J., and andPeters, E. (2013). Development and testing of an abbreviated numeracy scale: a Rasch analysis approach. J. Behav. Decision Making 26, 198-212. doi: $10.1002 / b d m .1751$

Conflict of Interest Statement: The author declares that the research was conducted in the absence of any commercial or financial relationships that could be construed as a potential conflict of interest.

Copyright $\odot 2019$ Bjälkebring. This is an open-access article distributed under the terms of the Creative Commons Attribution License (CC BY). The use, distribution or reproduction in other forums is permitted, provided the original author $(s)$ and the copyright owner(s) are credited and that the original publication in this journal is cited, in accordance with accepted academic practice. No use, distribution or reproduction is permitted which does not comply with these terms. 